\title{
MOTOR ACTIVITY IN PATIENTS WITH SUPRATENTORIAL UNILATERAL STROKE
}

\section{Danche Vasileva, Nikolai Izov, Ivan Maznev, Daniela Lubenova, Kristin Grigorova-Petrova}

\begin{abstract}
The aim of the study is to evaluate the effect of the specialized kinesitherapy methodology (SKTM) on motor activity in patients with supratentorial unilateral stroke in the chronic period (SUSChP).

Material and Methods

The study was conducted with 67 patients with SUSChP (56 patients are included in the experimental group - 32 men and 24 women, with the duration of the disease $7.8 \pm 2.0$ months, and 11 patients in the control group -9 men and 2 women, with the duration of the disease $7.3 \pm 1.5$ months).

To evaluate the changes, the motor capabilities are tracked with a modified Chedoke-McMaster test, and muscle tone with a modified Ashworth scale for upper and lower extremities that are relevant metric to evaluate the motor activity of the patients. The experimental group was conducted with a specialized 10-day KT treatment, which later continued to perform as an adapted exercise program at home for a period of 1 month. Control patients are following a conventional 10-day KT.

Results

After applying SKTM, the highest tendency towards improvement of motor activity is established in the 1st month for upper and lower extremities, with a level of significance during treatment $p<0.001$.

Conclusion

The applied SKTM to the experimental group, later continued as adapted exercise program at home, which significantly improves the motor activity of patients with supratentorial unilateral stroke in the chronic period compared with the usual kinesitherapeutic methodology applied in the control group.
\end{abstract}

Keywords: Kinesitherapy, Motor activity, Motor capabilities, Stroke, Chronic period

\section{Introduction}

Motor activity is an essential part of complex therapy in patients suffering from stroke. It has been shown that physically active people have a lower risk of stroke and fatal outcome than those with low physical activity. This dependence is due to the positive effect of physical activity on body weight, blood pressure, serum cholesterol, and glucose tolerance. Physical activity performed during leisure time (3-4 times/week, on average $40 \mathrm{~min}$ ) (Eckel et al., 2013; Kernan et al., 2013) have a favorable short-term effect in patients with mild stroke (Katsiki et al., 2011; Willey et al., 2011; Li, Siegrist, 2012). Modern neurorehabilitation and kinesitherapy (KT) have principal differences in acute, suboptimal (up to the $6^{\text {th }}$ month of the accident) and chronic (after 6 months) restoration phase. While its application during the first 6 weeks after the stroke stimulates and supports the spontaneous recovery of motor disorders, its role in the chronic period is not the actual recovery of the motor deficit, but the use of compensatory behavioral strategies to overcome it, which is associated with a bishhemistic reorganization. Unintentional brain cells are trained to perform certain functions (Titianova et al., 2008; Peppen et al., 2004). The recovery potential is increased by combining $\mathrm{KT}$ and pharmacotherapy (Krakauer, 2006; Dobkin, 2010; Bersano et al., 2010). Newer concepts offer intensive therapy with motor-related tasks that involve more functional skills. As a prognostic mark, the degree of damage to the corticospinal pathway is considered. Patient's relatives are trained to assist and support the day-to-day activities of the patient (Titianova, 2007; Lubenova, Titianova, 2012). It is known that after the KT, the patients are more independent, their mood improved and their activity level increased. There is a number of evidence that KT could be effective in motor control, but systemic comparisons of effectiveness across different types of treatment programs are limited (Duncan, 1997; Gordon et al., 2004; O'Sillivan, 2001). It has 
been shown that nearly $14 \%$ of stroke survivors achieve almost complete recovery of motor skills, between $25 \%-50 \%$ need support for daily activities, and other patients have permanent disability. Abnormal mobility is common in stroke survivors, especially in the elderly (Roth, Harvey, 2000).

\section{Purpose}

To investigate the early $\left(10^{\text {th }}\right)$ and the late $\left(1^{\text {st }}\right.$ month) effect of the application of the specialized KT method in patients with chronic hemiparesis, in comparison with the control group, which is the usual KT, on the motor activity.

\section{Material and methods}

The study was conducted in 67 patients with supratentorial unilateral stroke in the chronic period (56 patients in the experimental group (EG) - 32 males and 24 women with a disease duration of $7.8 \pm 2.0$ months and 11 patients in the control group (CG) 9 men and 2 women with disease duration $7.3 \pm 1.5$ months). The clinical characteristics of the contingent are presented in Table 1. A modified Chedoke-McMaster scale was used to determine the gravity of the phase that the $4^{\text {th }}$ and $5^{\text {th }}$ stage patients had a moderate degree of involvement, and the $6^{\text {th }}$ and $7^{\text {th }}$ stages had a slight degree of involvement (Cowland et al., 1993; Wade, 1992). On this basis, the patients were divided into two subgroups (moderate and mild).

Table 1. Clinical characteristics of the contingent at the start of the study

\begin{tabular}{llll}
\hline Parameters & Patients & Moderate degree & Mild degree \\
\hline Experimental group & $\mathrm{n}=56$ & $\mathrm{n}=33$ & $\mathrm{n}=23$ \\
Age & $63.2 \pm 8.8$ & $63.9 \pm 7.1$ & $62.3 \pm 10.9$ \\
Sex(men / women) & $32 / 24$ & $22 / 11$ & $10 / 13$ \\
Limitation periods (months) & $7.8 \pm 2.0$ & $8.3 \pm 2.2$ & $7.2 \pm 1.5$ \\
Localization (left / right) & $26 / 30$ & $16 / 17$ & $10 / 13$ \\
Control group & $\mathrm{n}=11$ & $\mathrm{n}=5$ & $\mathrm{n}=6$ \\
Age & $63.3 \pm 6.0$ & $63.6 \pm 5.3$ & $63.1 \pm 7.1$ \\
Sex (men / women) & $9 / 2$ & $5 / 0$ & $4 / 2$ \\
Limitation periods (months) & $7.3 \pm 1.5$ & $7.6 \pm 1.8$ & $7.0 \pm 1.2$ \\
Localization (left / right) & $5 / 6$ & $2 / 3$ & $3 / 3$ \\
\hline
\end{tabular}

$\overline{\mathrm{X}} \pm \mathrm{SD}$ - mean and standard deviation $E G$ - the experimental group, $K G$ - control group. The significance of the intra-group changes is defined by the binominal test. Intergroup significance of sex and localization is determined by U-criteria of Mann Whitney for independent samples, while for age and limitation period, a Student t-test for independent samples is attached.

To evaluate the changes, the motion capabilities were tracked through a modified Chedoke-McMaster test and muscle tone through Ashworth's modified upper and lower limb scales, which are current informative indicators for motor performance assessment. Patients from the EG were treated with a specialized 10-day KT, which was later performed as an adapted home exercise program for a period of 1 month. It is based on the basic principles of modern neurorehabilitation: to be individual, intensive and specifically oriented - tailored and focused on the individual needs of the patient; To realize the active involvement of the patient and his / her family during prolonged administration so as to ensure care that is tailored for the patient's needs throughout his life to achieve recovery and influence of late complications of the disease (Vasileva, Lubenova, 2014). A 10-day standard KT method with a 30 min duration was applied to CG patients

using traditional approaches to central motor neuron damage as outlined in the "Medical Standard on Physical and Rehabilitative Medicine" (Lubenova, Titianova, 2015). The two KT methods used are different in their duration of treatment, structure and included postural movements, walking, active upper limb movements and transfers).

\section{Statistics}

A set of statistical programs were used to quantify the received data. The Wilcoxon test was used to compare non-parametric parameters during treatment, and the Mann-Whitney U-criterion was used to determine the significance of differences between the groups. The Paired Samples Test is applied to compare parametric parameters.

\section{Results}

Comparison of patients in two groups did not show 
significant differences in age, gender, localization and disease duration. The evaluation was performed before KT, on the $10^{\text {th }}$ day and $1^{\text {st }}$ month after the start of treatment. The results of the traceability indicators of the changes in motor activity in patients with chronic ischemic stroke from the
EG and CG as well as the significance of changes in the course of treatment are presented in Table 2. The differences between the obtained and the baseline values as well as the significance of the changes between the two groups are presented in Fig. 1 and Fig. 2.

Table 2. Prospective comparative assessment of motor activity in the EG and CG

\begin{tabular}{lllll}
\hline Parameters & Groups & At the beginning & $10^{\text {th }}$ day & $1^{\text {st }}$ month \\
& EG $(\mathrm{n}=56)$ & $\bar{X}$ & $\overline{\mathrm{X}} \pm \mathrm{SD}$ \\
\hline CG $(\mathrm{n}=11)$ & $\overline{\mathrm{X}} \pm \mathrm{SD}$ & $5.2 \pm 0.7^{* * *}$ & $5.7 \pm 0.4^{* * *}$ \\
\hline Chedoke-McMaster - & EG & $4.2 \pm 0.7$ & $5.20 .7^{*}$ & $4.70 .9 \pm$ \\
Upper limb (stage) & CG & $4.4 \pm 0.7$ & 0.884 & 0.000 \\
& P & 0.390 & $5.7 \pm 0.5^{* * *}$ & $6.0 \pm 0.3^{* * *}$ \\
Chedoke-McMaster - & EG & $4.8 \pm 0.6$ & $5.80 .6 \pm *$ & $5.40 .9 \pm$ \\
Lower limb (stage) & CG & $4.90 .7 \pm$ & 0.600 & 0.001 \\
& P & 0.693 & $0.8 \pm 0.7^{* * *}$ & $0.4 \pm 0.5^{* * *}$ \\
Ashworth - Upper limb & EG & $1.6 \pm 0.6$ & $0.9 \pm 0.6^{*}$ & $1.20 .5 \pm$ \\
(points) & CG & $1.4 \pm 0.5$ & 0.972 & 0.000 \\
& P & 0.419 & $0.5 \pm 0.6^{* * *}$ & $0.1 \pm 0.3^{* * *}$ \\
Ashworth - Lower limb & EG & $1.1 \pm 0.6$ & $0.60 .6 \pm *$ & $0.9 \pm 0.5$ \\
(points) & CG & $1.2 \pm 0.3$ & 0.925 & 0.000 \\
\hline
\end{tabular}

$\overline{\mathrm{X}} \pm \mathrm{SD}-$ mean and standard deviation, ${ }^{* * *} p<0.001,{ }^{*} p<0.05-$ significant change compared to baseline in the course of treatment assessed by Wilcoxon Test; $P<0.001$ - significance of the change between the two groups measured by U-criteria of Mann-Whitney Test.

It was found that at the beginning of the treatment both groups had decreased motor activity. There are no significant differences in the baseline data between two groups. Compared with the baseline data in the experimental group, there is a significant improvement in the upper limb capabilities, as evidenced by the Chedoke-McMaster test. Similar are the changes in the lower limb. In absolute terms, the positive change was most pronounced on the $1^{\text {st }}$ month, with a level of significance $p<0.001$. The effect on motor restoration of the limbs is sustained and is maintained until the first month of follow-up in the EG. It means that patients are restored to the possibility of coordinated movements near normal. Unusual patterns of movement can occur only in fast and complex action. Control patients have significant improvement in motor activity that was observed on day 10, then the values decreased. Compared to the baseline, no change was observed in the $1^{\text {st }}$ month.

Similar are the results of tracking the muscle tone in the upper and lower limbs, according to the Ashworth scale before and after the KT in the EG. An improvement is noted between mild and missing spasticity. The effect of reducing the spontaneously increased muscle tone of the affected limbs is sus- tained and is maintained until the first month of follow-up.

In the CG, the decrease in muscle tone was observed on day 10 .

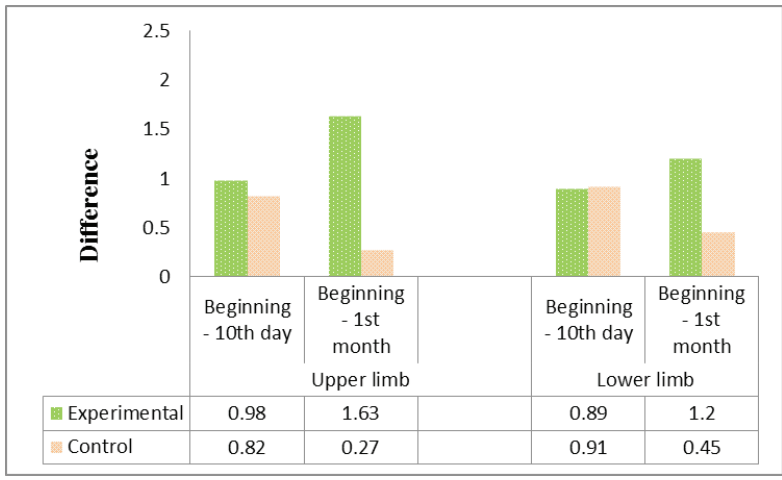

Figure 1. Changes in motor recovery presented as the difference between the results obtained and the baseline values in the two study groups, ${ }^{* * *} P<0.001$ - Significant change between the two groups during treatment, assessed by the U-criteria of the Mann-Whitney Test.

Similar changes in muscle tone are seen when compared between the two groups (Fig. 2). The effect of specialized kinesitherapy methodology (SKTM) is significantly better than standard KT at the 1 month of treatment (Fig. 2). 


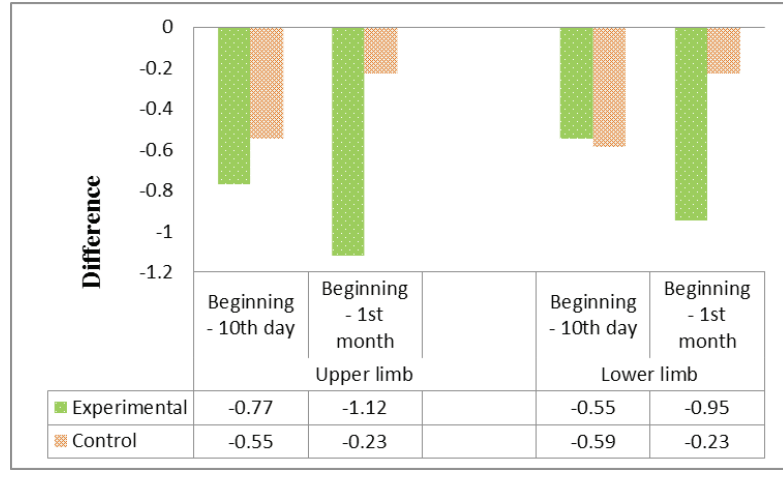

Figure 2. Changes in muscle tone, presented as difference between results and baseline values in the two groups studied, ${ }^{* *} P<0.001$ - Significant change between the two groups during the course of treatment as assessed by the Mann-Whitney U-Criterion Test

\section{Discussion}

The lasting positive effect in the EG may be related to various mechanisms where the applied targeted movements affect the functional capabilities of patients with chronic stroke in a chronic period. These basically include: functional upper and lower limb movements, body and pelvic control that normalize the control of the body's intact and affected parts, and the motor response sequence. It is essential to include walking instruction in the methodology, which leads to: normalizing the control of the lower limbs and facilitating the movement (Vasileva et al., 2015; Vasileva et al., 2015; Vasileva et al., 2017; Lubenova et al., 2008). The improvement on the $10^{\text {th }}$ day of onset treatment in the two groups is probably due to the fact that the methodologies used are moderate in intensity and are tailored to the patient's individual abilities.

Beneficial effect in patients in the EG remains significant in the one month follow-up, which necessitates the need for a sustained KT use of at least 4 weeks and appropriate individual training. Training in new methods, with the necessary length of time, changes the brain and creates a new motor stereotype (Lubenova, Titianova, 2015). Improved locomotor activity on the $10^{\text {th }}$ day in a hospital setting under the control of a therapist is maintained in the middle of life, which has been linked to the positive influence of the surrounding and psychosocial factors relevant to the performance of motor tasks. Apparently these home-based factors are beneficial and provide an opportunity to generalize acquired skills (Dijoseph, 1982; Iwarsson, Isacsson, 1997). Grigorova-Petrova K., (2014) confirms that the duration is essential for the recovery of patients with stroke in an acute period with a 4-week KT program. There is a significant improvement in everyday activities evaluated throughout the Barthel Index to moderate dependence on day-to-day activities of the $1^{\text {st }}$ month following the incident. The author demonstrates the positive effect of the applied KT in an acute period after ischemic stroke and the need for continuation of the KT to achieving patient independence in everyday life, which has been reported for most follow-up activities of the FIM test in this study (Grigorova-Petrova, 2014). Differences in mild and moderate changes can be explained by the fact that functional recovery involves more than the restitution of body functions. In particular, recent studies exploring human kinematics show that improving fine movements and gait is largely based on the use of compensatory motion strategies to help patients learn to cope with the existing neurological deficit (Kwakkel et al., 2004). The use of specialized KT has a beneficial effect on the functional mobility of patients with stroke in a chronic period. The effect is positive and continues until the end of the intervention period in the EG (Indredavik et al., 1998; O'Sullivan, 2007; Pollock et al., 2014).

\section{Conclusion}

The presented data clearly underline the different tendency of the changes in the all patients and the significant early and late effects of SKTM in patients with supratentorial unilateral stroke in the chronic period. In the EG, a significant improvement was observed on the $1^{\text {st }}$ month post-initiation of kinesitherapy, with a $\mathrm{p}<0.001$ level of significance during treatment, whereas in the controls the observed positive effect on day 10 decreased and patients regained baseline. The applied short-term kinesitherapy has no long-lasting effect.

\section{Literature}

Bersano, A., Ballabio, E., Lanfranconi, S., Corti, S., Locatelly, F., Baron, P., Bresolin, N., Parati, E., Candelise, L. (2010), Clinical studies in stem cells transplantation for stroke: a review, Curr Vase Pharmacol, Vol. 8, pp. 29-34. Cowland, C., Stratford, P., Ward, M. (1993), Measuring physical impairment and disability with the Chedoke-McMaster Stroke Assessment, Stroke, Vol. 24 No. 1, pp. 58-63.

Dijoseph, L. (1982), Indipendence through activity: mind, body and environment interaction in therapy, Am J Occup Ther, Vol. 36, pp. 740-744.

Dobkin, B. (2010), What matters in cellular transplantation for spinal cord injury: the cells, the rehabilitation or the best mix?, Neurorehabil Neural Repair, Vol. 24, pp. 7-9. Duncan, P. (1997), Synthesis of intervention trials to im- 
prove motor recovery following stroke, Top Stroke Rehabil, Vol. 3, pp. 1-20.

Eckel, R., Jakicic, J., Ard, J., Miller, N., Hubbard, V., Nonas, C., de Jesus, J., Sacks, F., Lee, I., Smith, S., Lichtenstein, A., Svetkey, L., Loria, C, Wadden, T., Millen, B, Yanovski, S. (2013), AHA/ACC Guideline on Lifestyle Management to Reduce Cardiovascular Risk. In Press. Circulation. 2013;00:000-000 DOI: 10.1161/01. cir.0000437740.48606.d1

Gordon, N., Gulanick, M., Costa, F., Fletcher, G., Franklin, B., Roth, E., Shephard, T. (2004), Physical Activity and Exercise Recommendations for Stroke Survivors: An AHA Scientific Statement From the Council on Clinical Cardiology, Subcommittee on Exercise, Cardiac Rehabilitation, and Prevention, Stroke, Vol. 35, pp. $1230-1240$.

Grigorova-Petrova, K., Lubenova, D., Dimitrova, A., Baldaranov, D., Lozeva, J. (2014), Feasibility of Early Physical Therapy Program In-Hospital Patients with Acute Ischemic Stroke, Macedonian Journal of Medical Sciences, Vol 7 No.3, pp. 452-455.

Indredavik, B., Bakke, F., Slordahl, S. (1998), Stroke unit treatment improves quality of life: a randomized controlled trial, Stroke, Vol. 315, pp. 895-899.

Iwarsson, S., Isacsson, A. (1997), On scaling methodology and environmental influences in disability assessments: the cumulative structure of personal and instrumental ADL among older adults in a Swedish rural district, Can J Occup Ther, Vol. 64, pp. 240-251.

Katsiki, N., Ntaios, G., Vemmos, K. (2011), Stroke, obesity and gender: a review of the literature, Maturitas, Vol. 69, pp. 239-243.

Kernan, W., Inzucchi, S., Sawan, C., Macko, R., Furie, K. (2013), Obesity: a stubbornly obvious target for stroke prevention, Stroke, Vol. 44, pp. 278-286.

Krakauer, J. (2006), Motor learning: its relevance to stroke recovery and neurorehabilitation, $\mathrm{Curr} \mathrm{Opin} \mathrm{Neu-}$ rol, Vol. 19, No. 1, pp. 84-90.

Kwakkel, G., Kollen, B., Lindeman, E. (2004) Understanding the pattern of functional recovery after stroke: facts and theories, Restor Neurol Neurosci, Vol. 22, pp. 281-299.

Li, J., Siegrist, J. (2012), Physical activity and risk of cardiovascular disease: a meta-analysis of prospective cohort studies, Int J Environ Res Public Health, Vol. 9, pp. 391-407.

Lubenova, D., Dimitrova, A., Ganchev, D. (2008), Characteristics of kinesitherapy in patients with agnosia after ischemic stroke in the undetermined hemisphere, Kinesitherapy, Vol. 1, pp. 12-20.

Lubenova, D., Titianova, E. (2012), Principles of modern neurorehabilitation, Neurosonology and cerebral hemodynamics, Vol. 8, No. 1, pp. 45-55.

Lubenova, D., Titianova, E. (2015), Neurorehabilitation, in Titianova, E. (Ed.), Neural Diseases Textbook - General Neurology. University Publishing House „St Kliment Ohridski", Sofia, pp. 249-259.

O'Sillivan, S. (2001), Strategies to improve motor control and motor learning, in O'Sillivan, S., Schmitz, T. (Ed.), Physical rehabilitation: assessment and treatment. 4-th
Ed, Philadelphia, Davis Company, pp. 363-368.

O'Sullivan, S. (2007), Stroke, in O'Sullivan S., Schmitz T. (Ed.), Physical rehabilitation. Philadelphia, Davis Company, pp. 704-768.

Peppen, R., Kwakkel, G., Harmeling-van der Wel, B., Kollen, B., Hobbelen, J., Buurke, J., et al. (2004), KNGF Clinical Practice Guideline for physical therapy in patients with stroke. Review of the evidence, Nederlands Tijdschrift voor Fysiotherapie, Vol. 114, No. 5 (Suppl).

Pollock, A., Baer, G., Campbell, P., Choo, P., Forster, A., Morris, J., Pomeroy, V., Langhorne, P. (2014), Physical rehabilitation approaches for the recovery of function and mobility following stroke, Cochrane Database of Systematic Reviews, 4-001920.

Roth, E., Harvey, R. (2000), Rehabilitation of stroke syndromes. In: Braddom R, ed. Physical Medicine and Rehabilitation. 2nd ed. Philadelphia, Pa: WB Saunders, pp. 1117-1163.

Titianova, E. (2007), Reorganization of motor control after unilateral stroke, Neurosonography and cerebral hemodynamics, Vol. 3, No. 1, pp. 42-47.

Titianova, E., Velcheva, I., Stamenov, B., Hristova, E., Karakaneva, S., Staikov, I., Grozdinski, L., Petrov, I. (2008), Algorithm for ultrasound diagnostics and therapeutic behavior in carotid pathology. Kontsensus of the Bulgarian Association of Neurosonology and cerebral hemodynamics, Neurosonology and cerebral hemodynamics, Vol. 4 No. 2, pp. 12-134.

Vasileva, D., Izov, N., Maznev, I., Lubenova, D., Mihova, M., Markovski, V., Nistor Cseppento, C. (2017), Changes in Kinetic Parameters of Gait in Patients with Supratentorial Unilateral Stroke in Chronic Period, Open Access Macedonian Journal of Medical Sciences, Vol. 5, No. 2, pp. 201-206.

Vasileva, D., Lubenova, D., Mihova, M., Dimitrova, A., Grigorova Pertova, K. (2015), Influence of kinesitherapy on balance reactions in patients with ischemic stroke in the chronic period, Open Access Macedonian Journal of Medical Sciences, Vol.3, No. 4, pp. 601-606.

Vasileva, D., Lubenova, D., Mihova, M., Dimitrova, A., Grigorova Pertova, K. (2015), Influence of kinesitherapy on gait in patients with ischemic stroke in the chronic period, Open Access Macedonian Journal of Medical Sciences, Vol.3, No. 4, pp. 619-623.

Vasileva, D., Lubenova, D. (2014), Adapted program for independent home rehabilitation in patients with chronic stroke. Sports and Science, Vol.58, No. 3, 61-72.

Wade, D. (1992), Measurement in neurological rehabilitation. University Press, Oxford.

Willey, J., Moon, Y., Paik, M., Yoshita, M., Decarli, C., Sacco, R., Elkind, M., Wright, C. (2011), Lower prevalence of silent brain infarcts in the physically active: the Northern Manhattan Study, Neurology, Vol. 76, pp. 2112-2118

Address for correspondence:

Ass.prof. Danche Vasileva, $\mathrm{PhD}$

Faculty of Medical Sciences

University "Goce Delchev"

St. Krste Misirkov 10-A

2000 Shtip, R. Macedonia

e-mail: dance.vasileva@ugd.edu.mk 